\title{
EARTHQUAKE HAZARD ALONG THE WESTERN COAST OF SOUTH AMERICA INFERRED FROM CONDITIONAL PROBABILITIES
}

\author{
Koravos G. ${ }^{1}$, Vougiouka G. ${ }^{2}$, Tsapanos T.M. ${ }^{1}$, Drakatos G. ${ }^{3}$ and Olasoglou E. ${ }^{1}$ \\ ${ }^{1}$ Aristotle University of Thessaloniki, Department of Geology, 54124, Thessaloniki, Hellas, \\ tsapanos@geo.auth.gr,gkoravos@sch.gr,eolaso@geo.auth.gr \\ ${ }^{2}$ Georgia E. Vougiouka, Department of Mathematics, Aristotle University of Thessaloniki, $54124 T$ \\ hessaloniki, HELLAS, georgiavuk@hotmail.com \\ ${ }^{3}$ National Observatory of Athens, Institute of Geodynamis, Thision, 11810, Athens, Hellas, \\ g.drakat@noa.gr
}

\begin{abstract}
The conditional probabilities method is considered to be an alternative approach in order to estimate the earthquake hazard. For this purpose, this technique was applied to the western side of South America, one of the most seismogenic regions of the world. The method is applied in six pre-determined zones which covered the whole examine area. The occurrence of the earthquakes as a function of time was assessed, using the conditional probabilities technique. The Kolmogorov-Smirnov test was applied in order to determine the distribution followed by the inter-arrival times between the successive past events. The test shows that the lognormal is the best fit distribution, for the scope of the present work.

The obtained results are in good accordance to the method applied. High probabilities are estimated for events with $M w \geq 7.0$. For the whole western part of South America, there is a probability about $64 \%$ for an earthquake occurrence with magnitude $M \geq 8.0$, during a time period of 20 years. Higher probability $(\approx 73 \%)$ was estimated for a time period of 50 years and for an earthquake of magnitude $M \geq 8.5$. This is clearly showed for the event of 1960, where the next (a posteriori procedure) earthquake of $M=8.8$ occurred on 2010.

Keywords: conditional probability, Kolmogorov-Smirnov test, lognormal distribution, seismic zones, South America.

\section{Пєрí $\eta \psi \eta$}

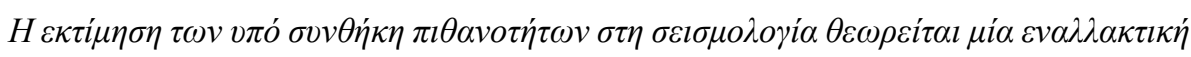

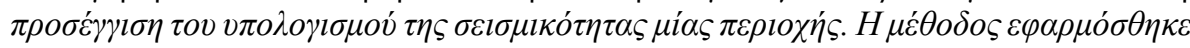

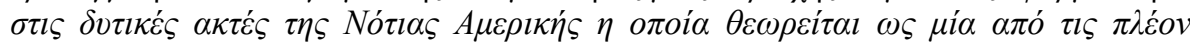

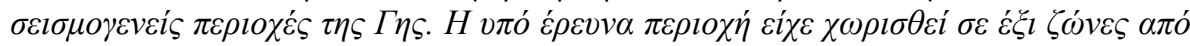

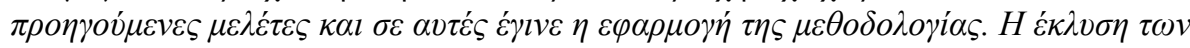

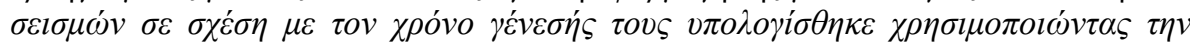

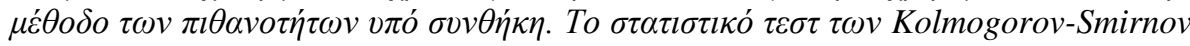

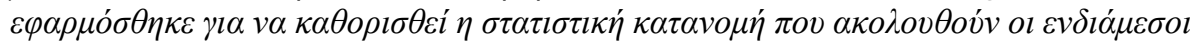

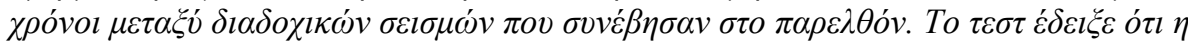

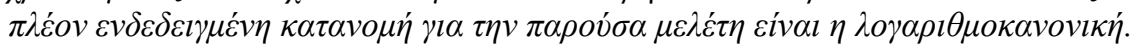




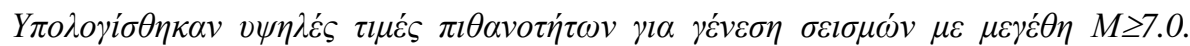

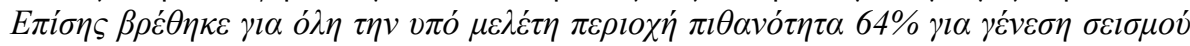

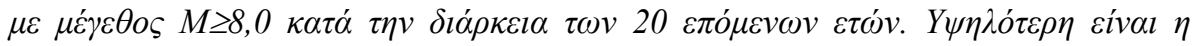

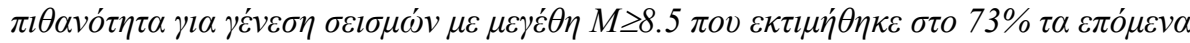

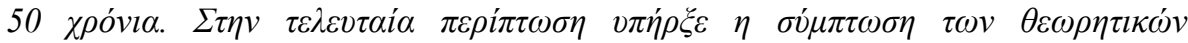

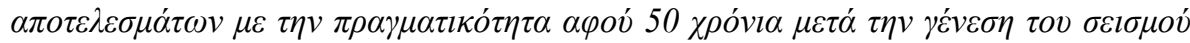

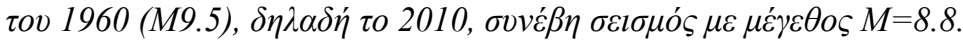

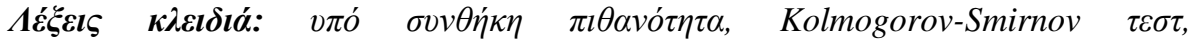

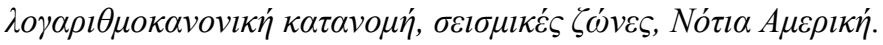

\section{Introduction}

South America is one of the most seismically active regions of the world. Especially, Chile and Peru were ranked in the second and the forth position, respectively, among fifty seismogenic countries of the world, in terms of their seismicity (Tsapanos and Burton, 1991).

The reason for the high seismicity level and other associated phenomena (e.g. deformation) is related to the lithospheric process of the region. Nazca plate seems to be of complicated tectonic structure (Bilek, 2010) and is subducting underneath the South America plate. The seismic activity is mostly concentrated along the coasts of the Pacific Ocean, where the subduction process takes place and reverse faulting dominates the tectonic regime (Suarez et al., 1990). The relative velocity of the convergence is about $9.3 \mathrm{~cm} / \mathrm{yr}$ (Casaverde and Vargas, 1984), while there were referred velocities like $8.5 \mathrm{~cm} / \mathrm{yr}$ (Quezada, 1997) and $9.0 \mathrm{~cm} / \mathrm{yr}$ (Dewey and Lamb, 1992). The main characteristic of the area is the generation of large to great earthquakes like the widely known event of 1960 with moment magnitude $\mathbf{M}_{\mathrm{w}}=9.5$. Very large earthquakes were referred or recorded since historical era up to now at the interface between the two plates. Descriptions back to 16th century provide information about very large shocks (e.g. the event of 1570 in Conception or the one of 1687 in Ica). The magnitudes and the return periods (100-150 years) of such events indicate that most of the $90 \%$ of the deformation, caused by the relative motion at the interface of the two plates, is released by earthquakes (Kelleher, 1972; Prince and Scheweller, 1978; Stein et al., 1986, Tsapanos and Christova, 2000).

Conditional probabilities can be considered as the quantity which allows the estimation of the likelihood that a region or an active fault is prone for the occurrence of a large event. McCann et al. (1979) stated a number of criteria in order to categorize the seismic potential. Later on, Nishenko and McCann (1981) used some tectonic and temporal criteria in order to estimate seismic potential for large earthquakes generation along segments of some major plate boundaries of the globe. Based on seismic potential technique, Nishenko (1985) estimated a probability of 59\% for the occurrence of an earthquake of $\mathrm{M} \geq 7.5$ along Chile. His estimation was verified by the occurrence of Valparaiso (Chile) earthquake (during 1985 with $M=7.8$ ). Nishenko (1991) estimated the seismic potential for plate boundary segments around the Pacific rim in terms of conditional probabilities, in order to find large earthquakes occurrence during the forthcoming years. Moreover, Tsapanos (2001) proposed the seismic zone and the magnitude interval $(M \geq 7.8)$ of the 2001 earthquake (near coast of Peru), by the application of a Markov - chain process. The probability estimated for this particular shock was about $65 \%$.

The paper confines itself to the reappraisal of the earthquake hazard along the western coast of South America, in terms of conditional probabilities.

\section{Data used}

The present study focuses in six pre-determined (Tsapanos, 2001) seismic zones (Fig. 1). These zones almost coincided with the zones defined by other researchers (Papadimitriou, 1993; Galanis et al., 2001). 


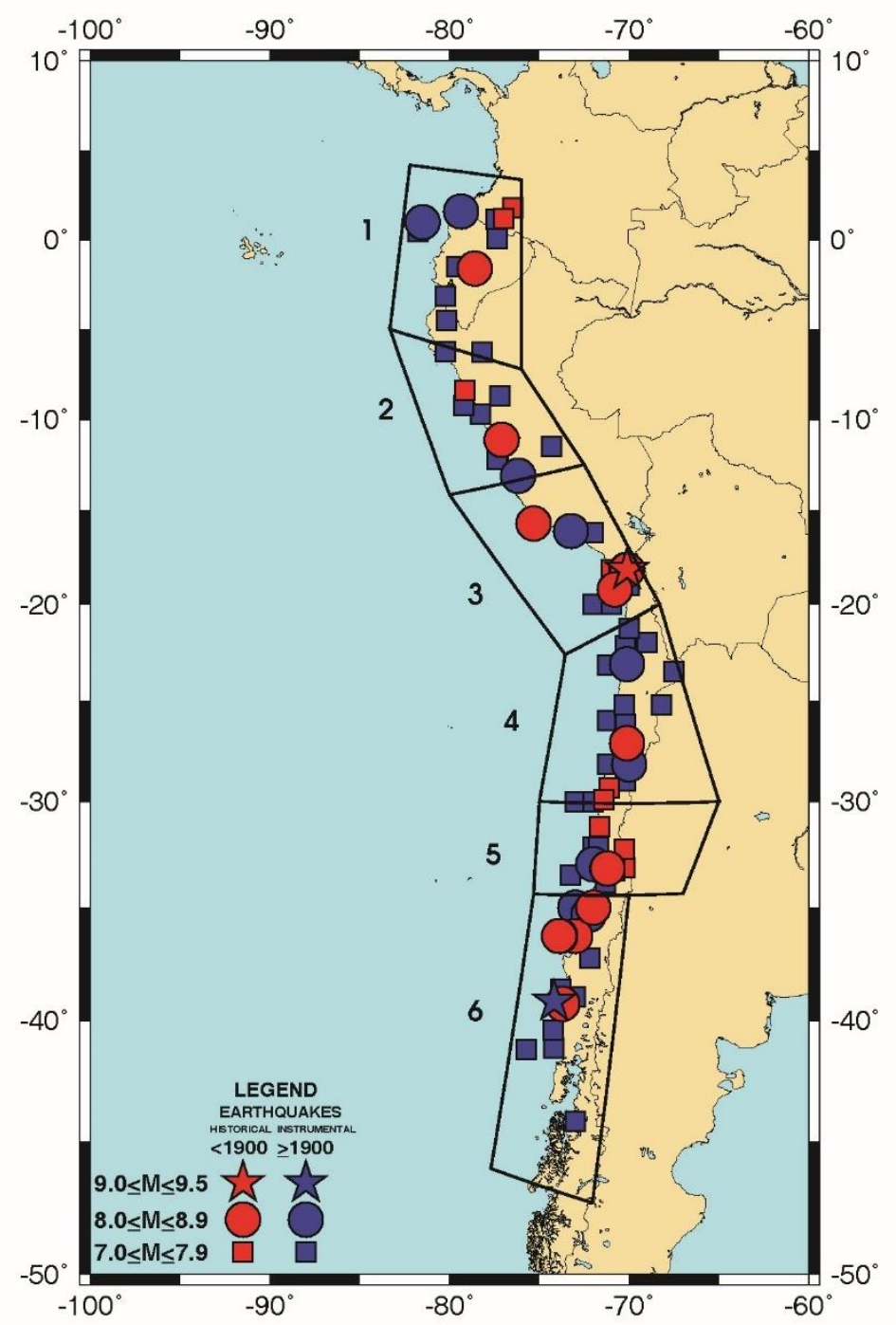

Figure 1 - Map of earthquake epicentres along the western side of the South America, is shown. The six zones considered are also revealed.

The initial data set $(M \geq 6.5)$ for South America's shocks was extracted from the data bank of NEIC. The data are restricted only to shallow earthquakes. The catalogue is free of depended events, like fore - and aftershocks, by applying the method proposed by Musson (2000). Due to the high seismicity of the area, the final catalogue adopted includes only large earthquake $(M \geq 7.0)$. The magnitude of the events in the catalogue is expressed as moment magnitude, $\mathbf{M}_{\mathrm{w}}$. In several cases, especially for historical and/or older earthquakes, the magnitudes were estimated as surface magnitudes, Ms. In such cases the Ms earthquake magnitudes were converted into Mw applied for this purpose the relation introduced by Scordilis (2006). The number of the data in each zone and their time interval, the mean and the standard deviation are listed in Table 1. 
Table 1 - The number of the data used and the time period for which data are available in each one of the six zones examined. The mean $\mu$ and the standard deviation $\sigma$ for each zone is tabulated, as well.

\begin{tabular}{|c|c|c|c|c|}
\hline ZONE & Number of data & Time period of data & $\boldsymbol{\mu}$ & $\boldsymbol{\sigma}$ \\
\hline 1 & 13 & $1797-2013$ & 0.186 & 0.656 \\
\hline 2 & 11 & $1619-2007$ & 1.007 & 1,520 \\
\hline 3 & 15 & $1604-2001$ & 0.549 & 1.064 \\
\hline 4 & 21 & $1796-1995$ & 0.538 & 1.162 \\
\hline 5 & 13 & $1575-1985$ & 0.515 & 1.145 \\
\hline 6 & 18 & $1570-2010$ & 0.798 & 1.384 \\
\hline
\end{tabular}

It is obvious that in each zone the data set includes both historical and instrumental events. It is interesting that the percentage of historical events varies from $47 \%$ (zone 3 ) to $62 \%$ (zone 5). The use of numerous historical events enriches the final data set at each zone and so the results are more precise.

\section{The method applied}

Several approaches exist concerning the estimation of the probability of recurrence of large earthquakes. The most important are the random and the conditional probability models.

The random model assumes that the recurrence time of an earthquake is randomly distributed. It adopts the Poisson distribution, where the probability of recurrence of an earthquake event is independent of the time elapsed since the last event.

The model of conditional probability for the earthquake recurrence assumes that there is dependence between the probability of recurrence and the time elapsed since the large previous earthquake.

In order to use the model of conditional probability, it is proved that the time $t$ of an earthquake event approximates the lognormal distribution better than the normal distribution. For this aim, the Kolmogorov-Smirnov test (K-S test) is applied. The test compares the sample of each zone with the reference probability function. In the case of normal distribution, the K-S test compares the sample of each zone with the standard normal distribution and the null hypothesis that the sample follows this distribution is rejected. In the case of lognormal distribution, knowing that if the time t follows the lognormal distribution, the $\log (\mathrm{t})$ is normally distributed, the K-S test compares the logarithms of data for each one of the six zones with the standard normal distribution and the null hypothesis is accepted. All the tests were done at level $\mathrm{a}=0.10$.

Equation 1 - Formula for the probability density function of $t$ :

$$
f(t)=\frac{1}{t \sigma \sqrt{2 \pi}} \exp \left[-\frac{(\ln t-\mu)^{2}}{2 \sigma^{2}}\right]
$$

where, the parameters denoted as $\mu$ and $\sigma$ are the mean and the standard deviation, respectively, of the logarithm's variables, which means

Equation 2 - Formula for the transformation of the log-normal distribution to standard normal:

$$
X=e^{\mu+\sigma Z}
$$

where, $\mathrm{X}$ is random variable, $\mathrm{Z}$ is a standard normal variable. Both parameters $\mu$ and $\sigma$ are portrayed in Table 1. 
In order to estimate the probability of recurrence of an earthquake, we estimate the conditional

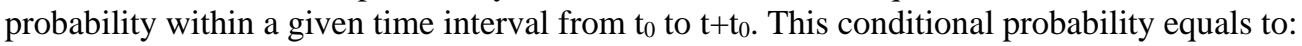

Equation 3 - Formula for the conditional probability:

$$
P(E)=\frac{F\left(t_{0}+t\right)-F\left(t_{0}\right)}{1-F\left(t_{0}\right)}
$$

where, $F(t)$ is the cumulative distribution function of the variable $t$ and can be expressed as the integral of its probability density function $\mathrm{f}(\mathrm{x})$ as follows:

\section{Equation 4 - Formula for the probability density function $\mathbf{f}(\mathbf{x})$ :}

$$
F(x)=\int_{0}^{x} f(t) d t
$$

From the equation (3) the conditional probability is estimated, for the given time interval from $t_{0}$ to $\mathrm{t}+\mathrm{t}_{\mathrm{o}}$ presupposing that no earthquake happened after the last prescribed event.

Fig. 2 delineates that the probability depends on the shape of the curve ( $\mu$ and $\sigma$ values) and of course to the width of the time window t. It is obvious that the conditional probability is rising up as the time window is widening.

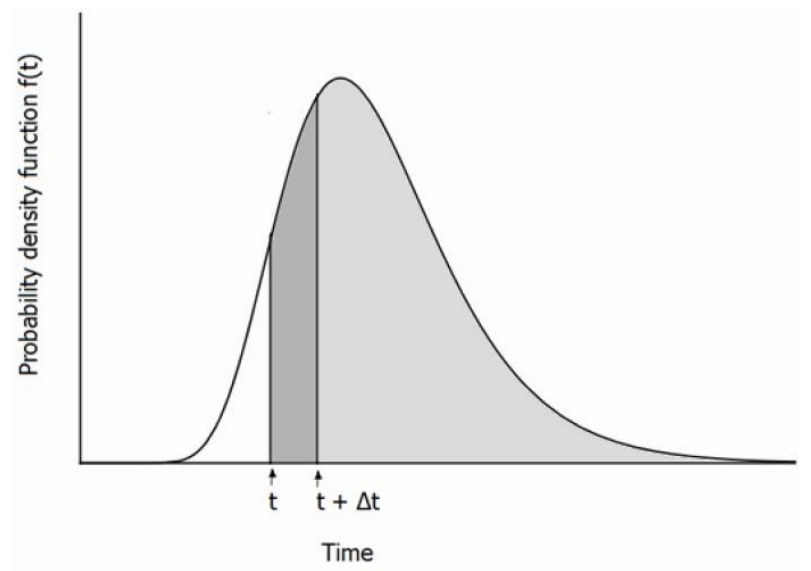

Figure 2 - Theoretical distribution of conditional probability for an earthquake inter-event time is shown. The earthquake inter-event time probability in the time interval $t, t+\Delta t$ is presented by the black "column" and is under the probability density curve. The ratio of the dark "column" area to the sum of the areas with both dark and grey colour outlines the conditional probability of the inter-event time of the next earthquake.

The data of the six zones, as well as for the whole South America, follow this distribution in a lower or higher degree.

\section{Results and Discussion}

In Fig. 3 the plots of the conditional probabilities against the time for the six zones are presented. As it is depicted in Fig. 3 the shape of the distribution of these probabilities in time depends on the values of the standard deviation $\sigma$ (http://en.wikipedia.org/wiki/Log-normal_distribution). A demonstration of the Cumulative Distribution Function, CDF (where $\mu=0$ ) is presented in Fig. 4, from which it is revealed that the values of $\sigma$ play a key role in the drawing of the distribution. For instance, when the value of $\sigma$ is equal to $1 / 8(0.125)$ the shape became very sharp (S-shape), e.g. zone 5. 

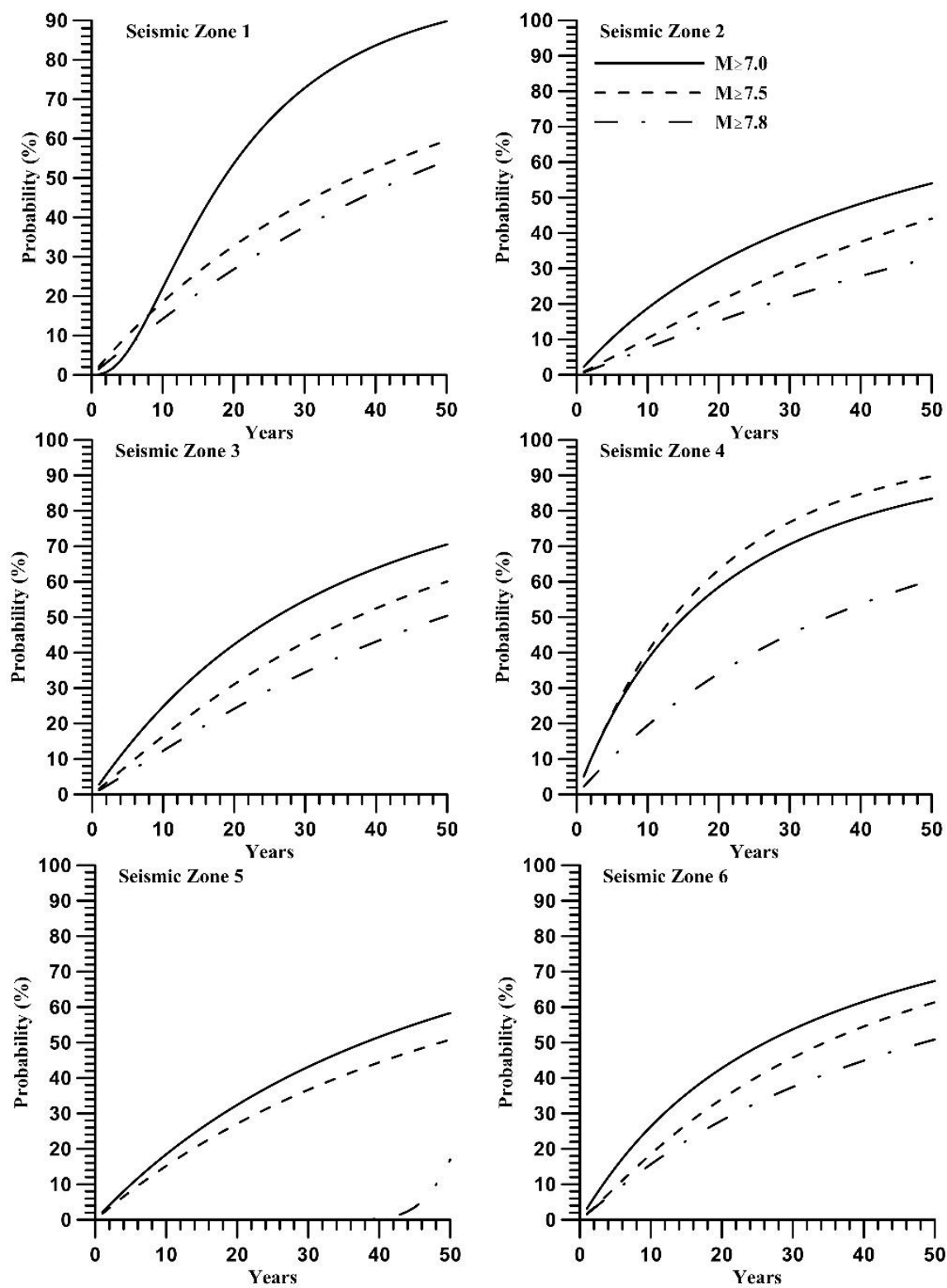

Figure 3 - The conditional probability of an earthquake inter-event time is shown, during a specific time period for the six zones considered, along the western part of South America.

The conditional probabilities seem very high for all time periods (e.g. for zone 1 and for the magnitudes $M \geq 7.0$ ). As it is depicted in Fig. 3 the conditional probabilities for magnitudes $M \geq 7.5$ and $M \geq 7.8$, are higher than the one of $M \geq 7.0$ in a time period of 8 and 6 years, respectively. Despite the values of $\sigma$, this can be interpreted if the probabilities of $M \geq 7.0$ would be estimated for longer time periods (e.g. 20 years). Very large earthquakes occurred in this zone in $1797(\mathrm{M}=8.3)$, in 1906 $(\mathrm{M}=8.8), 1958(\mathrm{M}=7.8), 1979(\mathrm{M}=8.1)$, as the last one generated in $2013(\mathrm{M}=7.0)$. The event of 1906 ruptured a segment of about $500 \mathrm{Km}$ long (Kanamori and McNally, 1982). 


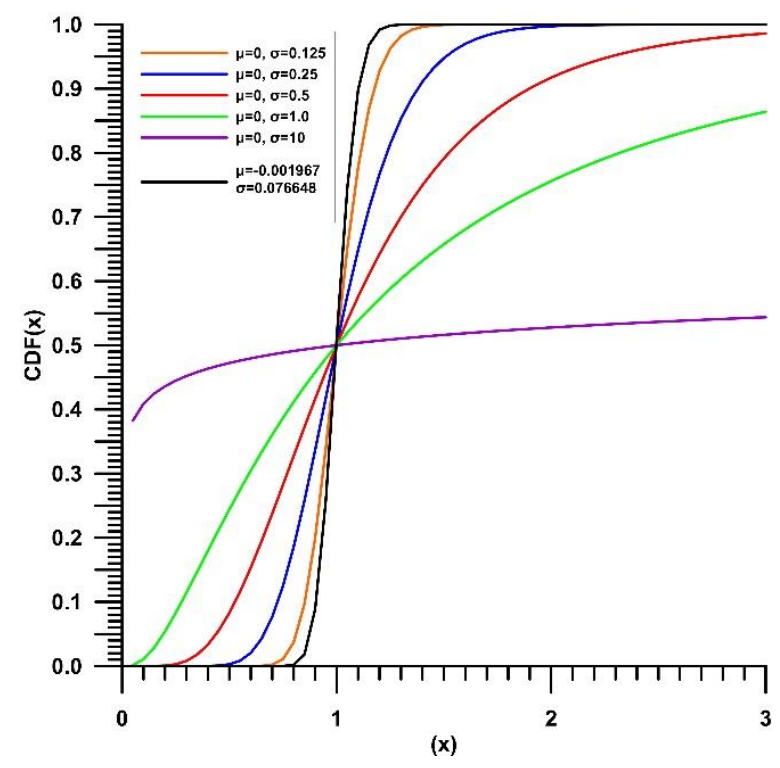

Figure 4 - Cumulative Distribution Function for various values of standard deviation ( $\sigma)$ and the value of mean $\mu=0$ (http://en.wikipedia.org/wiki/Log-normal_distribution). We added the curve (dark black) according to the obtained outputs $\sigma=0.076$ and $\mu \approx 0$.

In zone 2, the estimated conditional probabilities are low, exceed only the $50 \%$ (for $\mathrm{M} \geq 7.0$ ), in a time period of 50 years. Lower probabilities (44\% and 33\%) are also observed and for the other two magnitude ranges $\mathrm{M} \geq 7.5$ and $\mathrm{M} \geq 7.8$, respectively. They illustrate an ordinary distribution in time. The very large earthquakes in this zone are: $1619(\mathrm{M}=8.6), 1746(\mathrm{M}=8.7)$ in $1960(\mathrm{M}=7.8), 1970$ $(\mathrm{M}=7.9)$ and the last one in 2007 , with $\mathrm{M}=8.0$. For a 10 years time period and for $\mathrm{M} \geq 7.5$ a low conditional probability was estimated (10.3\%), while Nishenko (1991) estimated as $13 \%$ for the same time period.

Ordinarily distribution is also observed in zone 3. High conditional probabilities $(70.5 \%)$, in a time period of 50 years, is calculated for earthquakes of $M \geq 7.0$. Slightly lower probabilities of $60 \%$ are observed for magnitudes $M \geq 7.5$ and definitely lower about $43.5 \%$ for magnitudes $M \geq 7.8$. Very large earthquakes occurred in this zone since the historical epoch: $1604(\mathrm{M}=8.5), 1615(\mathrm{M}=8.8)$ in 1687 $(\mathrm{M}=8.7), 1831(\mathrm{M}=7.8), 1868(\mathrm{M}=9.0) 1877(\mathrm{M}=8.3), 1942(\mathrm{M}=8.2)$ and the last one is in 2001 $(\mathrm{M}=8.4)$. Nishenko (1985) suggested conditional probabilities of $20 \%$, for the next 10 years and for large earthquakes. Comparable results were estimated in the present study, where the conditional probability is about at $16.5 \%$ level for a 10 -years time window.

An unregulated distribution is depicted in zone 4. Statistically, it behaves like the distribution of zone 1. Very high values are observed for the conditional probabilities, which reached the $90 \%$, in a time period of 50 years and for $M \geq 7.5$. The probabilities are slightly lower (83\%) for the earthquakes of magnitude $\mathrm{M} \geq 7.0$ in a time period of 50 years. This lower pattern is observed from the beginning of the time period up to its end. Conditional probability reached the value of $58 \%$ for earthquakes of magnitude $\mathrm{M} \geq 7.8$ in a time period of 50 years. The very large earthquakes reported in this zone are: $1819(\mathrm{M}=8.3), 1918(\mathrm{M}=7.9), 1922(\mathrm{M}=8.5), 1946(\mathrm{M}=7.9), 1966(\mathrm{M}=7.8)$ and $1995(\mathrm{M}=8.0)$.

Zone 5 is of special interest because for magnitude level $\mathrm{M} \geq 7.8$ it shows an abnormal distribution. The conditional probabilities estimated are of intermediate values $(58.3 \%$, for $\mathrm{M} \geq 7.0)$, in a time period of 50 years, while a bit lower $(50 \%)$ are the probabilities estimated for the magnitude range of $\mathrm{M} \geq 7.5$. Both exhibit an ordinary distribution in time. The very large earthquakes of this zone occurred in: $1730(\mathrm{M}=8.7), 1822(\mathrm{M}=8.5), 1906(\mathrm{M}=8.2)$ and $1985(\mathrm{M}=8.0)$. The number of 
earthquakes that occurred during the historical era is predominant $(\approx 60 \%)$ in this zone. This could be one of the reasons that the earthquakes having magnitudes $M \geq 7.8$ show this kind of distribution. The time interval is generally long ( $\geq 35$ years) and the conditional probabilities are more reliable for long time periods (Fig. 5). Fig.5a shows the distribution for short time period (50 years), while Fig. 5b illustrates the same distribution for longer time-window (150 years). Historical records, concerning the very large earthquakes, point out that the recurrence time period along the examined area is larger than 60 years (Kelleher, 1972). According to Nishenko (1991) the average recurrence time for this zone is $95 \pm 10$ years. But as it is aforementioned the values of $\sigma$ is the key of the shape of the distribution. For the zone the calculated value is $\mu=-0.0019$, which practically is zero or tend to zero and $\sigma=0.076$. Based on these values we set on Fig. 4 the new curve (in dark black), in order to compare the obtained $\sigma$ value given that the $\mu$ value is practically the same, (tends to zero). The new curve fits much better to those values with $\sigma$ less than 0.125 . So we conclude that indeed $\sigma$ controls the shape of the conditional probability curve.
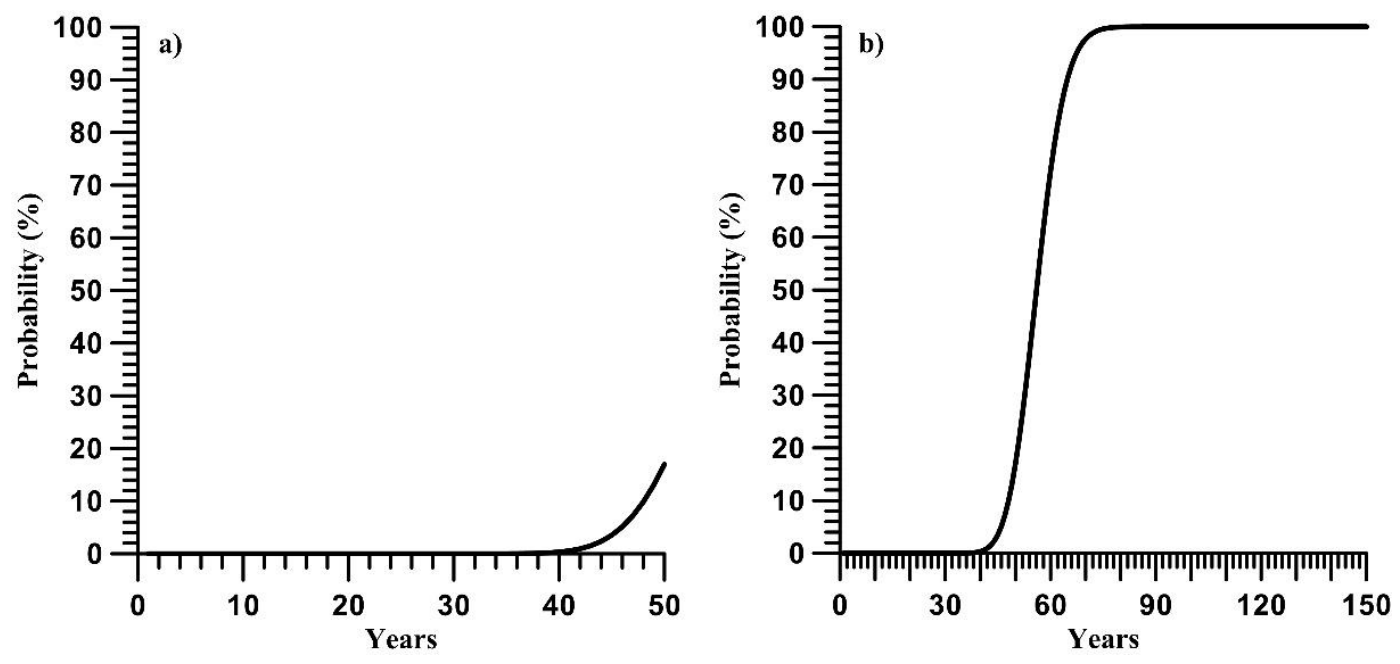

Figure 5 - The conditional probabilities of zone 5 and for magnitude interval $M \geq 7.8$ are shown: a) for a range up to 50-years time period, and b) for a range up to150-years time period.

Zone 6 seems to be the active seismogenic part of the examined area and more specifically during the historical epoch, given that about $70 \%$ of the very large earthquakes along the western coast of South America occurred in this zone. The estimated conditional probabilities are high $67.3 \%$ (for $\mathrm{M} \geq 7.0)$, in a time period of 50 years. Lower probabilities $(61.2 \%$ and $50.8 \%)$ are also observed and for the other two magnitude ranges $\mathrm{M} \geq 7.5$ and $\mathrm{M} \geq 7.8$, respectively. The very large earthquakes in this zone are: $1570(\mathrm{M}=8.3), 1575(\mathrm{M}=8.5), 1647(\mathrm{M}=8.5), 1657(\mathrm{M}=8.0), 1751(\mathrm{M}=8.5), 1835$ $(\mathrm{M}=8.2), 1837(\mathrm{M}=8.0), 1914(\mathrm{M}=8.2), 1960(\mathrm{M}=9.5)$ and the last one occurred in 2010 with $\mathrm{M}=8.8$. Conditional probabilities for time periods of $10,20,30,40$ and 50 years, for earthquakes with magnitude $M \geq 7.0$ in the six zones in which South America was divided, are listed in Table 2. Conditional probabilities in time are also estimated for earthquakes ranged in magnitudes $\mathrm{M} \geq 8.0$ and $\mathrm{M} \geq 8.5$ (Table 3).

Numerous earthquakes of such magnitudes occurred along the entire western coast of South America. The area is very productive in such events and already three earthquakes occurred during the present century (2001 $\mathrm{M}=8.4,2007, \mathrm{M}=8.0$ and $2010 \mathrm{M}=8.8)$. 
Table 2 - Conditional probabilities estimated for earthquakes with $M \geq 7.0$ in each zone for the next 10, 20, 30, 40 and 50 years from the present time.

\begin{tabular}{|c|c|c|c|c|c|}
\hline Years /Zones & $\mathbf{1 0}$ & $\mathbf{2 0}$ & $\mathbf{3 0}$ & $\mathbf{4 0}$ & $\mathbf{5 0}$ \\
\hline 1 & 22.62 & 59.30 & 79.65 & 89.54 & 94.40 \\
\hline 2 & 18.81 & 31.70 & 41.10 & 48.30 & 54.01 \\
\hline 3 & 24.77 & 42.30 & 54.74 & 63.78 & 70.52 \\
\hline 4 & 38.15 & 58.48 & 70.55 & 78.25 & 83.44 \\
\hline 5 & 18.48 & 32.41 & 43.14 & 51.58 & 58.33 \\
\hline 6 & 26.32 & 42.75 & 53.70 & 61.51 & 67.34 \\
\hline
\end{tabular}

Table 3 - The conditional probabilities estimated of earthquakes with magnitudes $M \geq 8.0$ and $M \geq 8.5$, along the western side of South America. The estimations are for the next 10, 20, 30, 40, 50 and 100 years, from the present time.

\begin{tabular}{|c|c|c|}
\hline Time Periods & $\mathbf{M} \geq \mathbf{8 . 0}(\boldsymbol{\%})$ & $\mathbf{M} \geq \mathbf{8 . 5}(\boldsymbol{\%})$ \\
\hline 10 & 38.25 & 17.19 \\
\hline 20 & 62.77 & 37.75 \\
\hline 30 & 76.41 & 53.70 \\
\hline 40 & 84.34 & 65.25 \\
\hline 50 & 89.19 & 73.53 \\
\hline 100 & 97.52 & 91.70 \\
\hline
\end{tabular}

Due to these shocks, low conditional probabilities are computed for the next 10-years. The probabilities are high during the next 30 years. It is very interesting that the "recent" earthquake of $2010(M=8.8)$ occurred fifty years after the $1960(M=9.5)$ earthquake, the largest event of the world up to now. The conditional probability along the west side of South America for a 50-years time window and for earthquakes with $\mathrm{M} \geq 8.5$ is estimated equal to $73.5 \%$.

\section{Conclusions}

It is widely known that an earthquake is the result of the strain energy released in a location, which originates a seismic slip in the collision of two lithospheric plates. This energy is accumulated in the interface of two plates for tens or hundreds of years and depends, between others, on the velocity of the under-thrusting plates. Slow and fast collision velocities reflect to longer or shorter recurrence time for an earthquake, respectively. The inter-event time of earthquakes as a function of time, as well as their recurrence time were assessed, using the conditional probabilities technique. This technique was applied in six pre-determined zones along the western side of South America, one of the most seismogenic regions of the world, due to the collision between Nazca and South America plates. In two of them (zones 4 and 5) some abnormalities observed showed that greater events have greater probability of inter-event time. This may due to the quality of the data because we have greater number of large earthquake during the historic epoch than in present era $\left(20^{\text {th }}\right.$ and $21^{\text {st }}$ century). As a general conclusion we can say that the results of the detailed analysis of the last event inter-event time show that the technique of the conditional probability seems to be a more advanced methodology and considered as a useful tool for the earthquake hazard mitigation. It is interesting that zone 1 showed the highest conditional probabilities for an earthquake occurrence with magnitude, $M w \geq 7.0$. During the review process of the present paper and specifically on $16^{\text {th }}$ of April 2016, an earthquake with $\mathrm{Mw}=7.8$ struck the coastal region of this zone, given that the previous event with $\mathrm{Mw} \geq 7.8$ occurred during 1979 ( $\approx 40$ years). For this time span the estimated conditional probability is about $90 \%$ (Table 2 ). 


\section{References}

Bilek, S.L., 2010. Seismicity along the South American subduction zone: Review of large earthquakes, tsunamis and subduction zone complexity, Tectonophysics, 495(1-2), 2-14.

Casaverde, L.A. and Vargas, J.N., 1984. Seismic risk in Peru, Proc. Of the 8th world conference on earthquake engineering, I, 93-100, July 21-28, San Francisco California U.S.A.

Dewey, J.F. and Lamb, S.H., 1992.Active tectonics in Andes, Tectonophysics, 205, 79-95.

Galanis, O.Ch, Tsapanos, T.M., Papadopoulos, G.A. and Kiratzi, A.A., 2001. An alternative Bayesian statistics for probabilistic earthquake prediction in Mexico, Central and South America, Bull. Geol. Soc. Greece, XXXIV/4, 1485-1491, http://en.wikipedia.org/wiki/Lognormal_distribution.

Kanamori, H. and McNally, K.C., 1982. Variable rupture model of the subduction zone along the Ecuador-Columbia coast, Bull. Seismol. Soc. of Am., 72(4), 1241-1253.

Kelleher, J.A., 1972. Rupture zones of large south American earthquakes and some predictions, $J$. Geophys. Res., 77, 2087-2103.

McCann, W.R., Nishenko, S.P., Sykes, L.R. and Krause, J., 1979. Seismic gaps and plate tectonics: Seismic potential for major boundaries, Pageoph., 117, 1082-1147.

Musson, R.M.W., 2000. Generalised seismic hazard maps for the Pannonian Basin using probabilistic methods, Pageoph., 157(1/2), 147-169.

Nishenko, S.P., 1985. Seismic potential for large and great interplate earthquakes along the Chilean and southern Peruvian margins of South America: A quantitative reappraisal, Journ. Geophys. Res., 90, 3589-3615.

Nishenko, S.P., 1991. Circum-Pacific seismic potential: 1989-1999, Pageoph., 135, 169-259.

Nishenko, S.P. and McCann, W.R., 1981. Seismic potential for the world's major plate boundaries: 1981. In: Earthquake Prediction, An International Review, Maurice Ewing Ser., Vol. 4, Simpson, D.W. and Richards, P.G., eds., American Geophys. Union, Washington D.C., 20-28.

Papadimitriou, E.E., 1993. Long term earthquake prediction along the western coast of South and Central America based on a time predictable model, Pageoph., 140, 301-316.

Prince, R.A. and Scheweller, W.J., 1978. Dates, rates and angles of faulting in the Peru-Chile trench, Nature, 271, 743-745.

Quezada, F.J., 1997. Seismic observation in Chile, Bull. Intern. Inst. Seismol. Earthq. Engin., 31, 243-259.

Scordilis, E.M., 2006. Empirical Global Relations Converting $\mathrm{M}_{\mathrm{s}}$ and $\mathrm{m}_{\mathrm{b}}$ to Moment Magnitude, Journ. Seismology, 10(2), 225-236.

Stein, S., Engeln, J.E., De Meto, C., Gordan, R.G., Woods, D.R., Lundgren, P., Argus, D., Quibble, D., Stein, C., Weistein, S. and Wiens, D.A., 1986. The Nazca South America convergence rate and the recurrence of the grate Chilean earthquake, Geophys. Res. Lett., 13, 713-716.

Suarez, G., Gagnepain, J., Cisternas, A., Hatzfeld, D., Molnar, P., Ocola, L., Roecker, S.W. and Viode, J.P., 1990. Tectonic deformation of the Andes and the configuration of the subducted slab in central Peru: results from a microseismic experiment, Geophys. J. Intern., 103, 1-12.

Tsapanos, T.M., 2001. The Markov model as a pattern for earthquakes recurrence in South America, Proc. of the 9th Intern. Congr., Athens, September 2001, 1611-1617.

Tsapanos, T.M. and Burton, P.W., 1991. Seismic hazard evaluation for specific seismic regions of the world, Tectonophysics, 195, 153-169.

Tsapanos, T.M. and Christova, C.V., 2000. Some preliminary results of the worldwide seismicity estimation: a case study of seismic hazard evaluation in South America, Ann. di Geofis., 43, $11-22$. 